\title{
SIGNAL TO NOISE RATIO IMPROVEMENT OF LOWER ATMOSPHERIC SIGNALS USING WAVELETS
}

\author{
G S SATHISH $^{1}$, S NARAYANA REDDY ${ }^{2}$, P SRINIVASULU $^{3}$, P. KAMARAJ ${ }^{4}$ \\ M.Tech, Dept. of ECE, SVUCE, SV University, Tirupati, India ${ }^{1}$ \\ Professor, Dept. of ECE, SVUCE, SV University, Tirupati, India ${ }^{2}$ \\ Scientist/Engineer-SG, National Atmospheric Research Laboratory (NARL, Gadanki, Tirupati, India ${ }^{3}$ \\ Scientist/Engineer-SC, National Atmospheric Research Laboratory (NARL), Gadanki, Tirupati, India ${ }^{4}$
}

\begin{abstract}
Lower Atmospheric Wind Profiler (LAWP) is used to provide continuous high resolution wind measurements in the lower atmosphere. Signal processing of this atmospheric radar is necessary to estimate the wind profiler moments and signal to noise ratio (SNR). The signals, which are processed in the present work has been obtained from the LAWP at National Atmospheric Research Laboratory (NARL), Gadanki, India. SNR computation is an important parameter in signal processing. This paper discusses improvement of SNR using wavelets for LAWP signals. In this paper wavelet denoising is used to improve SNR. Denoising is performed by selecting a DB10 wavelet. SNR for this data is computed for original signal and de-noised signal. Results show that there is $7 \mathrm{~dB}$ improvement in SNR after denoising using DB10 wavelet for LAWP signals.
\end{abstract}

Keywords: Wavelet, DB10, Denoising, Signal to Noise Ratio.

\section{INTRODUCTION}

Observations of wind velocity profiles are very important for studying meteorological phenomena and for weather to $3-6 \mathrm{~km}$, in clear air, which are very weak and forecasting. The L-band Lower Atmospheric Wind contaminated with clutter. These radars are sensitive to Profiler (LAWP) is used for conducting research in the hydrometer and are useful to study lower atmosphere. National Atmospheric Research precipitation/convection phenomena [1].

Laboratory (NARL) at Gadanki $\left(13.47^{\circ} \mathrm{N}, 79.18^{\circ} \mathrm{E}\right)$ near

Tirupati, India has been operating this $1280 \mathrm{MHz}$, atmospheric radar for studying structure and dynamics of the lower atmosphere. The block diagram is shown in fig 1. LAWP Radar consists of a simplified active micro strip patch $16 \times 16$ array, solid state TR modules, a passive two dimensional beam forming network, which can generate 81 usable beams, a Direct-IF Digital receiver, a PC based Radar Controller. These radars employ bi-phase coding (pulse compression) with complementary codes, to achieve better range resolution with maximum average power (height coverage). These radars receive the echoes
Radar wind profiler derives information on the dynamic atmosphere behavior by making use of variations in amplitude and frequency of radio waves which are transmitted from radar system, backscattered by the atmospheric refractive index irregularities and received by the radar system again. The LAWP specifications are shown below (Table 1). Radar wind profilers use either Doppler beam swinging (DBS) technique or spaced antenna (SA) technique for measuring the atmospheric winds. Present work uses DBS technique for measuring the atmospheric winds [2]. 
International Journal of Advanced Research in Computer and Communication Engineering Vol. 3, Issue 10, October 2014

A) Doppler Beam Swinging technique: It is the most commonly used technique for wind velocity measurements. One antenna beam is pointed toward zenith, and two beams are pointed at oblique angles in the range $10-20^{\circ}$ off-zenith with orthogonal azimuths (threebeam system). The oblique beams provide a measurement of the horizontal velocity and the vertical beam provides a direct measurement of the vertical velocity. Radial velocity measurements are made at each specified height along each beam. For each height, the radial velocities measured from three beams are used to derive the eastwest (zonal), north-south (meridional), and vertical components of the wind [3]. The raw data is processed and wind velocity components are obtained. The data processing steps of shown below (Fig 2).

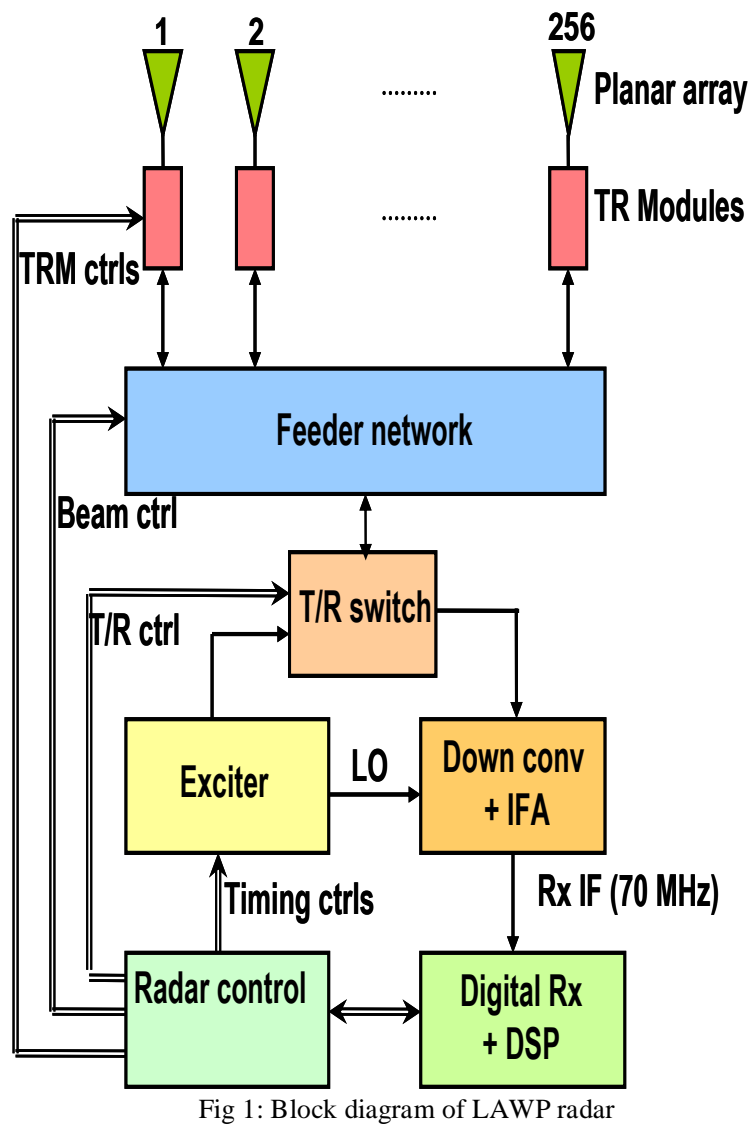

\section{B) LAWP SPECIFICATIONS:}

\section{WAVELETS}

A wavelet is a wave like oscillation with amplitude that begins at zero, increases, and then decreases back to zero. Wavelet transformation is one of the most popular candidates of the time-frequency transformations.
TABLE I

LAWP RADAR SPECIFICATIONS

\begin{tabular}{|l|l|}
\hline $\begin{array}{l}\text { Frequency } \\
\text { Technique }\end{array}$ & $1280 \mathrm{MHz}$ \\
\hline Antenna & $\begin{array}{l}\text { Active patch array } \\
16 \times 16(2.8 \mathrm{~m} \times 2.8 \mathrm{~m})\end{array}$ \\
\hline Beam width & $4.5^{\circ}$ \\
\hline Tx / Rx type & Solid state TR modules(256) \\
\hline Peak power & $2 \mathrm{KW}$ \\
\hline Pulse width & $0.25-8$ micro seconds \\
\hline Feed type & Passive 2-D beam forming network \\
\hline Receiver & $\begin{array}{l}\text { Super heterodyne Direct IF digital } \\
\text { receiver }\end{array}$ \\
\hline $\mathrm{R}_{\text {MIN }}$ & $100 \mathrm{~m}$ \\
\hline $\mathrm{R}_{\mathrm{MAX}}$ & $\begin{array}{l}3-6 \\
12 \mathrm{~km} \text { (during precipitation) }\end{array}$ \\
\hline
\end{tabular}

Wavelet transform decomposes a signal into a set of basis functions. These basis functions are called wavelets. Wavelets are obtained from a single prototype wavelet $\mathrm{y}(\mathrm{t})$ called mother wavelet by dilations and shifting

$\psi_{\mathrm{a}, \mathrm{b}}(\mathrm{t})=\frac{1}{\sqrt{a}} \psi\left(\frac{t-b}{a}\right)$

An analyzing function $\psi(\mathrm{t})$ is classified as a wavelet if the following mathematical criteria are satisfied [4]. 
International Journal of Advanced Research in Computer and Communication Engineering Vol. 3, Issue 10, October 2014

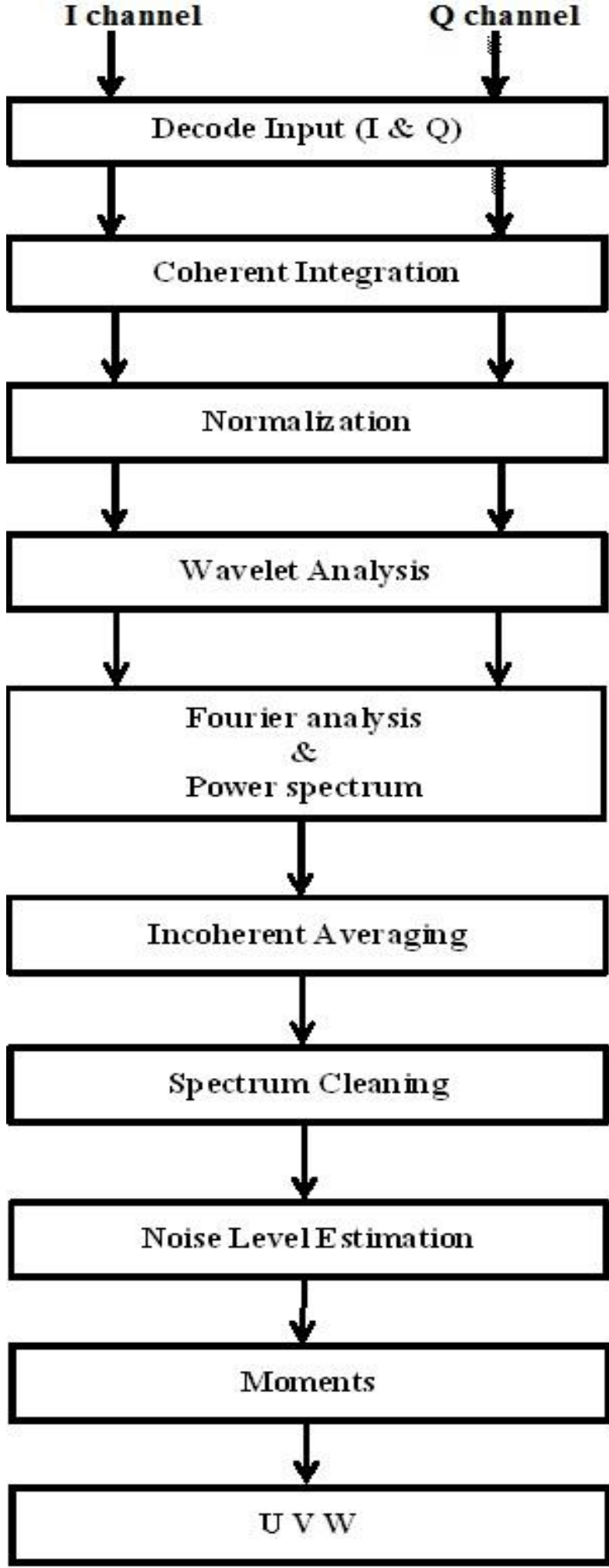

Fig 2: Data processing steps of LAWP Radar

\section{WAVELET DENOISING}

Wavelet analysis is one of the most important methods for removing noise and extracting signal from any data. The de-noising application of the wavelets has been used in Spectrum cleaning of the atmospheric signals. There are many types of wavelets available. The wavelet families like symlets, coiflets, daubechies, haar, etc., have their own specifications like filter coefficients, reconstruction filter coefficients. Wavelet analysis can often compress or de-noise a signal without appreciable degradation. The term 'de-noising', describing various schemes which attempt to reject noise by damping or thresholding in the wavelet domain. The aim of this study is to investigate the wavelet function that is optimum to identify and de-noise the radar signal (Fig 3).

The basic steps required for wavelet denoising:

\section{A) Selection of Wavelet:}

There are many types of wavelets available (Haar, Daubechies, Coiflets, etc.) with different properties among which select one according to the requirement (Fig 4)

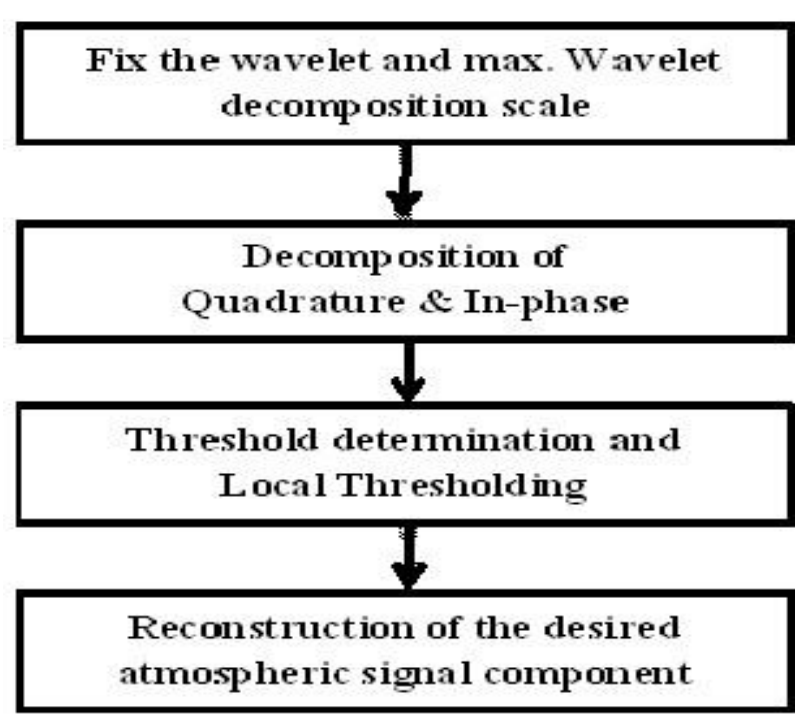

Fig 3: Block diagram for wavelet denoising scheme

i) Daubechies: The Daubechies family is named after Ingrid Daubechies who invented the compactly supported orthonormal wavelet, making wavelet analysis in discrete time possible [5]. The wavelet and scaling function for 
International Journal of Advanced Research in Computer and Communication Engineering Vol. 3, Issue 10, October 2014

Daubechies exist up to order 20. Higher order Daubechies functions are not easy to describe with an analytical expression. In general the Daubechies wavelets are chosen to have the highest number of vanishing moments (Fig 5). The order of the Daubechies functions denotes the number of vanishing moments, or the number of zero moments of the wavelet function. Larger the number of vanishing moments, better the frequency localization of the decomposition. The dependence between wavelet coefficients on different scales decays with increasing wavelet order. The order of the wavelet functions can be compared to the order of a linear filter. The Daubechies wavelets are compactly supported orthogonal wavelets.

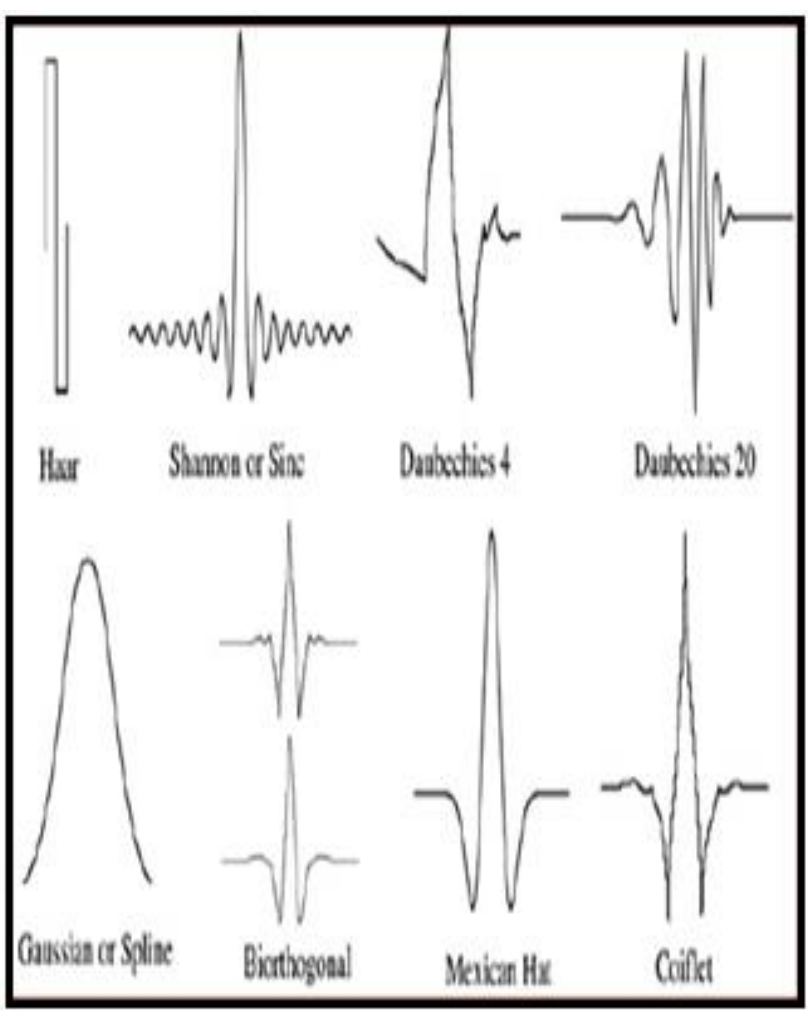

Fig 4: Examples of types of wavelets.

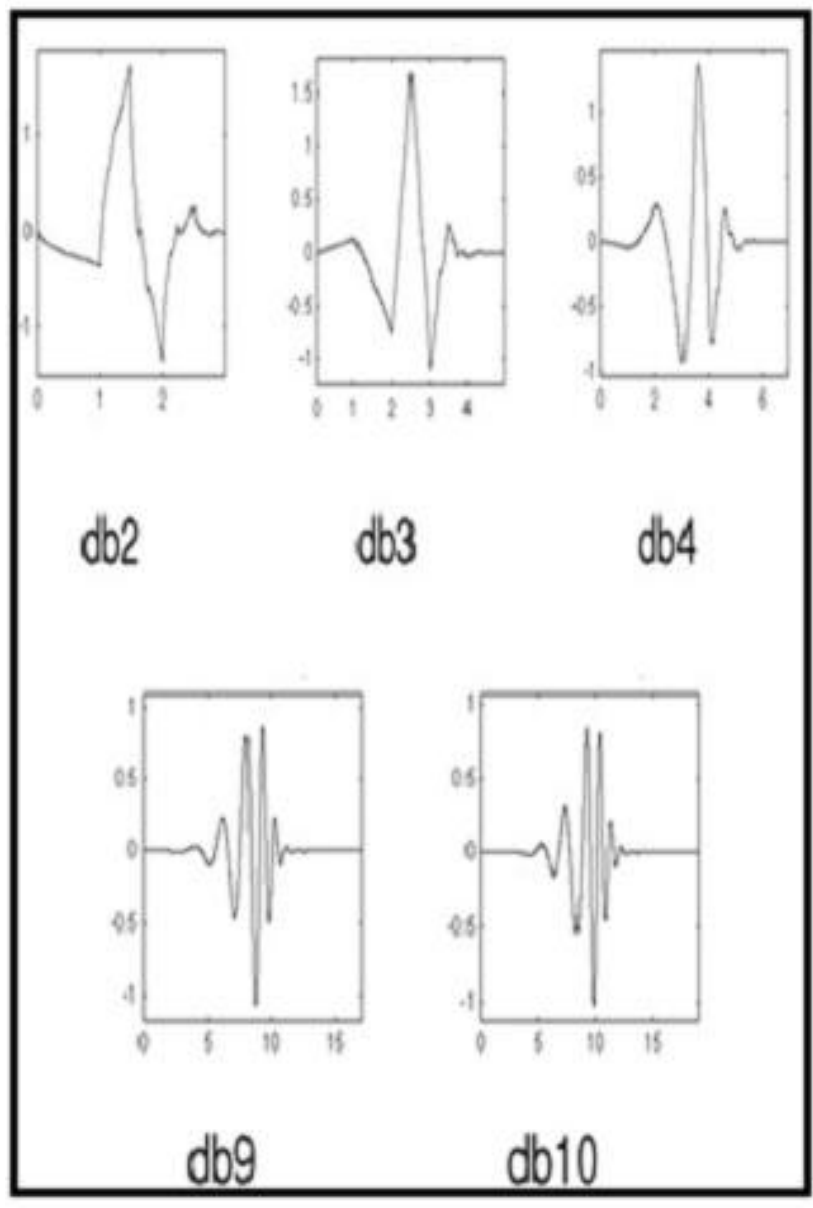

Fig 5: Types of Daubechies wavelets

ii) DB10 WAVELET: Daubechies 10 belongs to Daubechies family. The properties of this wavelet are asymmetric, orthogonal and bi-orthogonal. In this project selected wavelet for denoising is DB10 (Fig 6).

\section{B) Obtaining Wavelet Transform Coefficient:}

Compute the wavelet decomposition of the signal at the selected level $\mathrm{N}$ separately for I data and Q data of the received raw data signal. Here decomposition of signal is performed at level 3 . 


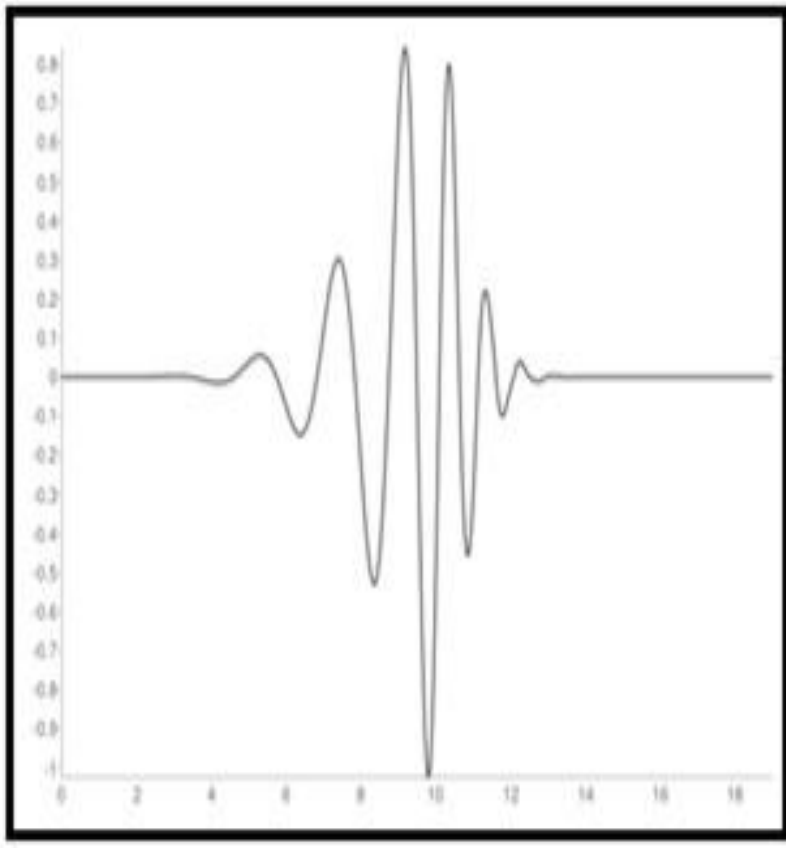

Fig 6: DB10 wavelet

\section{C) Selection of Threshold:}

The denoising and feature detection of signals using the wavelet transform is done by representing the signal by a small number of coefficients. This wavelet shrinkage is based on thresholding, as developed by Donoho and Johnstone [6]. The signal is composed into L levels before thresholding is applied. There are two types of thresholding, hard and soft thresholding with threshold (Fig 7). Hard thresholding zeros out small coefficients, resulting in an efficient representation. Soft thresholding softens the coefficients exceeding the threshold by lowering them by the threshold value. When thresholding is applied, no perfect reconstruction of the original signal is possible. In the proposed work hard thresholding is used. In addition to these, there is minimaxi, rigrsure, heursure threshold techniques present [6]. Each of these techniques has a unique behavior suitable for de-noising a particular type or class of signals. Thresholding can be done manually by selecting the desired coefficients according to different levels.

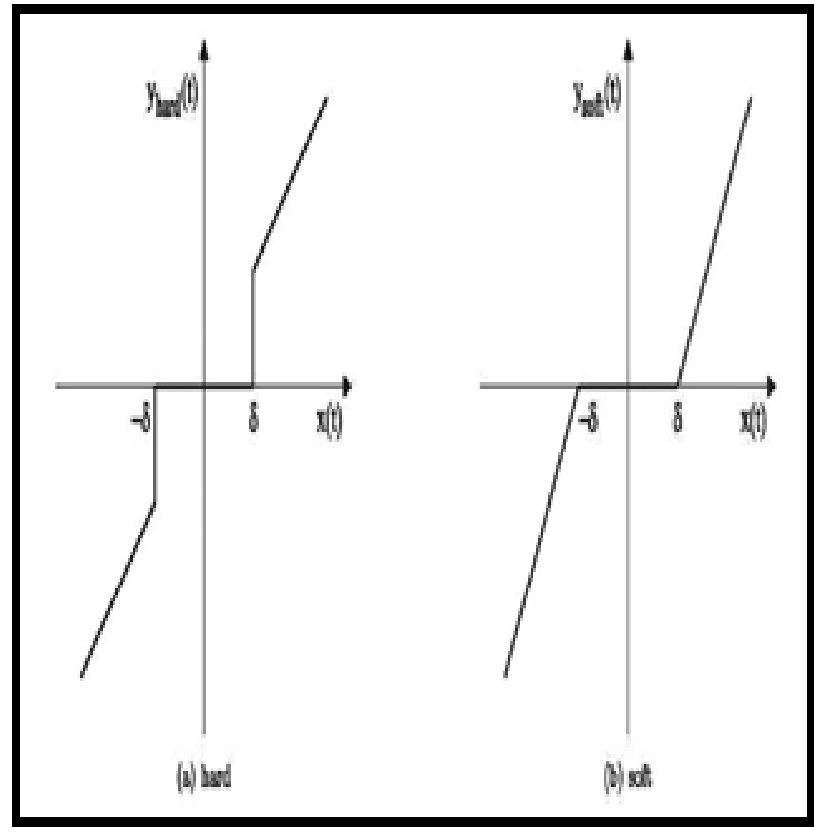

Fig 7: Thresholding

\section{D) Reconstruction:}

Reconstruct the signal using the approximation coefficients of level $N$ and the modified detail coefficients of levels from 1 to $N$.

IV. 2014

Algorithm for Doppler profile using DB10 wavelet:

- DC removal from the raw data using Hilbert transform technique.

- FFT computation for the raw data.

- Signal to noise ratio is computed for each range bin [7].

- The raw data is de-noised using DB10 wavelet.

- The above two steps 2 and 3 are repeated until all range bin data were processed.

\section{RESULTS}

The results shown in this paper were computed for north direction. The application of the above algorithm to radar data and the results are shown below (Fig 8). The Doppler 
International Journal of Advanced Research in Computer and Communication Engineering

Vol. 3, Issue 10, October 2014

profile and SNR plots for original data and wavelet denoised data are shown below (Fig 9).

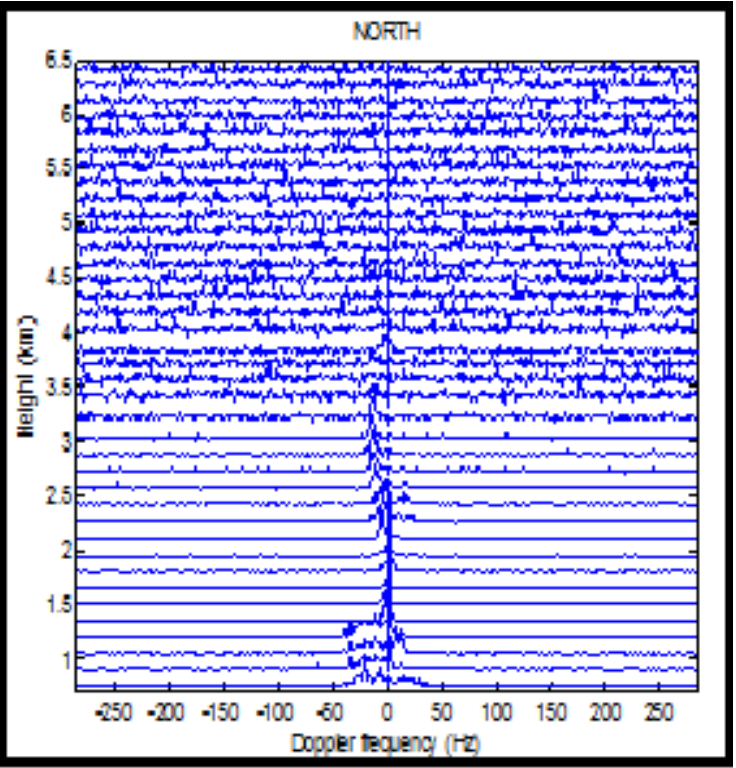

(a) Before denoising

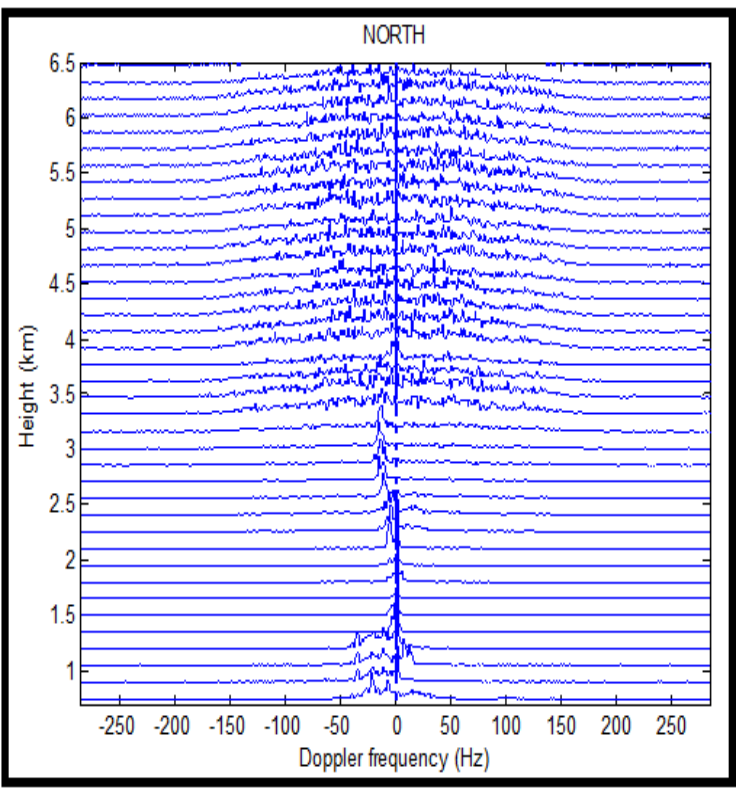

(b) After denoising

Fig 8: Doppler Profile

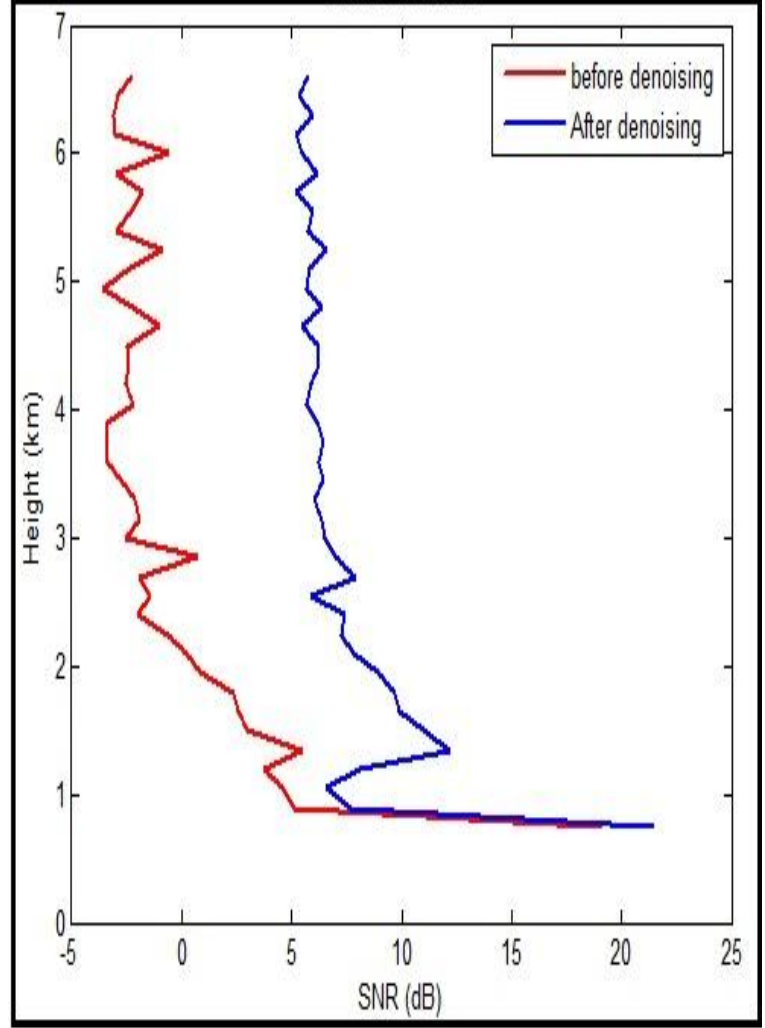

Fig 9: SNR Comparison.

\section{CONCLUSIONS}

In this paper we have discussed about improvement of signal to noise ratio of LAWP Radar signals using wavelets. SNR is improved by minimizing the noise of signal through wavelet denoising. The improvement is observed by comparing original signal and denoised signal. From our above discussion we conclude that an improvement of $7 \mathrm{~dB}$ is observed after denoising.

\section{REFERENCES}

[1] "1280 MHz Active Array Radar Wind Profiler for Lower Atmosphere: System Description and Data Validation," P. Srinivasulu, P. Yasodha, P. Kamaraj.

[2] P. Srinivasulu, "Development of UHF Wind Profiling Radar for Lower Atmospheric Research Applications”. National Atmospheric Research Laboratory, Gadanki.

[3] V. K. Anandan, "Atmospheric Data Processor - Technical and User reference manual," NARL.

[4] Addison P S (2002), The Illustrated Wavelet Transform Handbook, IOP Publishing Ltd., ISBN0-7503-0692-0.

[5] Daubechies I (1990), "The Wavelet Transform, Time-Frequency Localization and Signal Analysis", IEEE Transformation and Information Theory, Vol. 36, pp. 961-1005.

[6] Donoho D L and Johnstone I M (1994), "Threshold Selection for Wavelet Shrinkage of Noisy Data", IEEE.

[7] Hildebrand, P. H., R. S. Sekhon, "Objective determination of the noise level in Doppler spectra”, J. Appl. Meteorol., pp808-811, 1974 
International Journal of Advanced Research in Computer and Communication Engineering Vol. 3, Issue 10, October 2014

\section{BIOGRAPHIES}

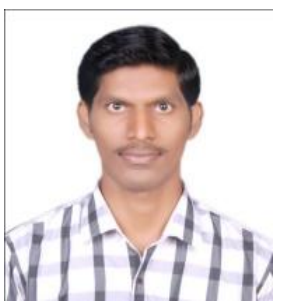

Mr. G. S. SATHISH completed his B.Tech in Electronics \& Communication Engineering at Sri Venkateswara University College of Engineering (SVUCE), SV University, Tirupati, INDIA in 2012. He is pursuing his M.Tech Degree with specialization Communication Systems (CS) at SVUCE SV University, Tirupati, INDIA.

His area of interest include signal processing, communication systems.

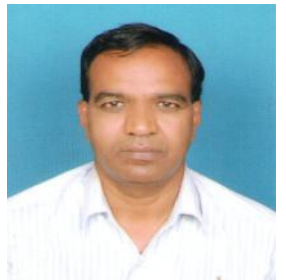

Dr. S. Narayana Reddy worked as Scientist in SAMEER in the design of MST RADAR system for 4 years and later joined as Assistant Professor in the Department of EEE at S.V. University Tirupati, INDIA. He has 25 years of experience in teaching and research. Presently he is working as Professor in the department of ECE at S.V.University. He is life Member of ISTE, fellow of IETE, fellow IE(I). He has published more than 80 papers in various National and International papers/conferences and guided 9 Ph.D scholars, His current interests include radar systems, signal processing and antenna systems.

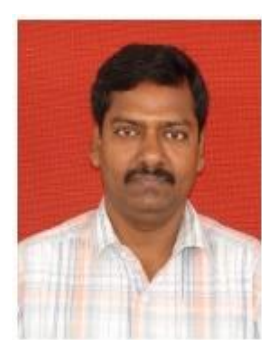

Dr. P. Srinivasulu completed his B.Tech (ECE) at REC Warangal and M.Tech (Microwave Engineering) at IIT Kharagpur in 1989 and 1991 respectively. He joined NARL in 1991. He is involved in the installation and commissioning of the VHF Indian MST Radar and L-band Boundary Layer Radar at NARL. He successfully developed active array atmospheric radars at HF, VHF and L-band frequencies. His areas of interest include active aperture radars, 3-D radar imaging and radar calibration.
Mr. P. Kamaraj completed his B.E.(E.C.E) at Anna University, Chennai, in 2004 and M.E (VLSI) at Anna University in 2009. He joined NARL in 2006. He is involved in the development, installation and commissioning of the L-band radar wind profilers, Pilot active phased array VHF Radar, HF Radar Interferometer at NARL. His areas of interest include active phased array radars and radar calibration. 